\title{
Analisis postur Kerja Dengan Metode Rapid Upper Limb Assesment (RULA) Pada Operator Bar Bending Di PT.XYZ
}

\author{
Nustin Merdiana Dewantari \\ Program Studi Teknik Industri, Universitas Sultan Ageng Tirtayasa, Kota Cilegon \\ E-Mail : nustin md@untirta.ac.id
}

\begin{abstract}
Abstrak - PT. XYZ merupakan perusahaan yang melakukan kegiatan pengusahaan, pembangunan pengoperasian, perawatan (operation and maintenance), serta pengembangan dan pengelolaan properti bisnis. Sebagai perusahaan yang bergerak di bidang konstruksi yang melibatkan manusia tidak lepas dari kenyamanan dan rasa nyeri pada operator yang bekerja, khususnya pada operator bar bending sehingga harus dikurangi penyebab ketidaknyamanan tersebut. Proses untuk mengurangi hal tersebut dengan menggunakan RULA (Rapid Upper Limb Assesment) yang diketahui untuk menilai postur dan gerakan kerja. Operator Bar Bending di PT.XYZ yang diperiksa adalah tubuh segmen A dan segmen B. Tubuh segmen A meliputi bagian lengan atas dan bawah sedangkan segmen B meliputi leher, punggung dan kaki, untuk mengetahui skor RULA. Hasil penilaian postur kerja pada operator bar bending menunjukan harus ada investigasi lebih lanjut dan perlunya perhatian untuk perbaikan segera. Tubuh bagian kiri menunjukan skor akhir sebesar 5 dan tubuh bagian kanan menunjukan skor 4. Dari hasil tersebut peneliti memberikan saran perbaikan berupa alat bantu berupa kursi pada operator bar bendingdanhasil setelah penggunaan alat bantu nilai skor RULAmenjadi berkurang.
\end{abstract}

Kata kunci- Kenyamanan kerja, RULA, perbaikan

\begin{abstract}
PT. XYZ is a company that conducts business activities, operations development, maintenance and operation and management of business property. As a company involved in the construction sector involving humans, it is not free from the comfort and pain of working operators, especially in bending bar operators, so the causes of discomfort should be minimized. The process to reduce this is to use a known Rapid Upper Limb Assessment to evaluate posture and movement. The Bending Bar Operators in PT XYZ were examined for segment $A$ and segment $B$. The body of segment A included the upper and lower arms, while segment B covered the neck, back and legs, to determine the RULA score. The results of the postoperative assessment of bending bar operators indicate that further investigation is needed and attention is needed for immediate improvement. The left side of the body shows the final score of 5 and the right body shows the score of 4. From this result the researchers provide suggestions for improvement in the form of help in the form of bends to the bending bar operator and the results after the use of the RULA score help.
\end{abstract}

Keywords - Work comfort, RULA, improvements

\section{Pendahuluan}

$\mathrm{B}$ ekerja dialami hampir oleh masyarakat Indonesia, baik itu sektor pertanian, perdagangan,jasa kemasyarakatan, kehutanan dll. Jumlah penduduk bekerja pada triwulan I tahun 2018 sebanyak 127,07 juta orang [1]. Bekerja pada dasarnya menggunakan perangkat yang ada pada tubuh. Hampir seluruh atau sebagian anggota tubuh digunakan ketika bekerja. Dalam bekerja tentu saja adanya pergerakan, secara statis maupun dinamis. Bekerja secara statis dalam waktu yang lama diketahui lebih sakit dibanding bekerja secara dinamis.

PT. XYZ merupakan salah satu perusahaan yang melibatkan banyak tenaga manusia, dalam konsep ergonomi dimana human centered design menjadi pijakan. Secara umum tujuan dari penerapan ergonomi adalah meningkatkan kesejahteraan fisik dan mental pekerja [2]. Ada beberapa penyebab ketidaknyamanan dan kesehatan dalam bekerja diantaranya karena alat, lingkungan tempat kerja, maupun metode kerja. Desain alat bantu atau mesin kerja dapat menyebabkan postur kerja dan gerakan kerja kita menyesuaikan meskipun terdapat ketidaknyaman ketika kita bekerja. Dari studi pendahuluan yang dilakukan sebelumnya didapatkan kondisi pekerja bar bending yang mengalami rasa sakit dan ketidaknyamanan ketika membuat besi ring pada lengan atas dan batang tubuh saat rotasi.

Rapid Upper limb assessment (RULA) adalah metode yang tepat untuk mengidentifikasi keluhan nyeri pada tubuh. Penelitian sebelumnya [3] melakukan penelitian pada PT.XYZ Surabaya menghasilkan bahwa metode RULA merupakan metode yang tepat untuk mengetahui keluhan musculoskeletal yang dialami oleh pekerja. Penelitian sebelumnya mengenai RULA dengan bantuan softwareCatia V5 dan ergofellow pernah dilakukan oleh [4] dengan objek pada perakitan mobil di India.

Tujuan dari penelitian ini adalah untuk mengetahui kondisi skor RULA serta postur kerja yang berpotensi bahaya musculoskeletal disorder pada operator bar bending kemudian mengetahui rekomendasi perbaikan yang dapat dilakukan.

\section{Metode Penelitian}

Penelitian dimulai dari proses studi literatur dan observasi langsung ke PT.XYZ untuk mengenal dan mengetahui kondisi yang dihadapi oleh PT.XYZ melalui wawancara dengan pihak terkait. Data yang sudah terkumpul hasil observasi kemudian dirumuskan untuk mencari rumusan masalah, tujuan penelitian dan batasan masalah yang akan 
dicari. Pengumpulan data lanjutan mengenai kondisi operator bar bending ketika bekerja menggunakan dokumentasi kemudian diolah untuk mencari nilai RULA dengan bantuan software Catia V5 dan Ergofellow, kondisi yang diperoleh terkini kemudian diberikan usulan perbaikan menggunakan alat bantu kursi dan dihitung kembali skor RULA setelah perbaikan, analisa hasil akhir beserta kesimpulan dan saran maka penelitian selesai.

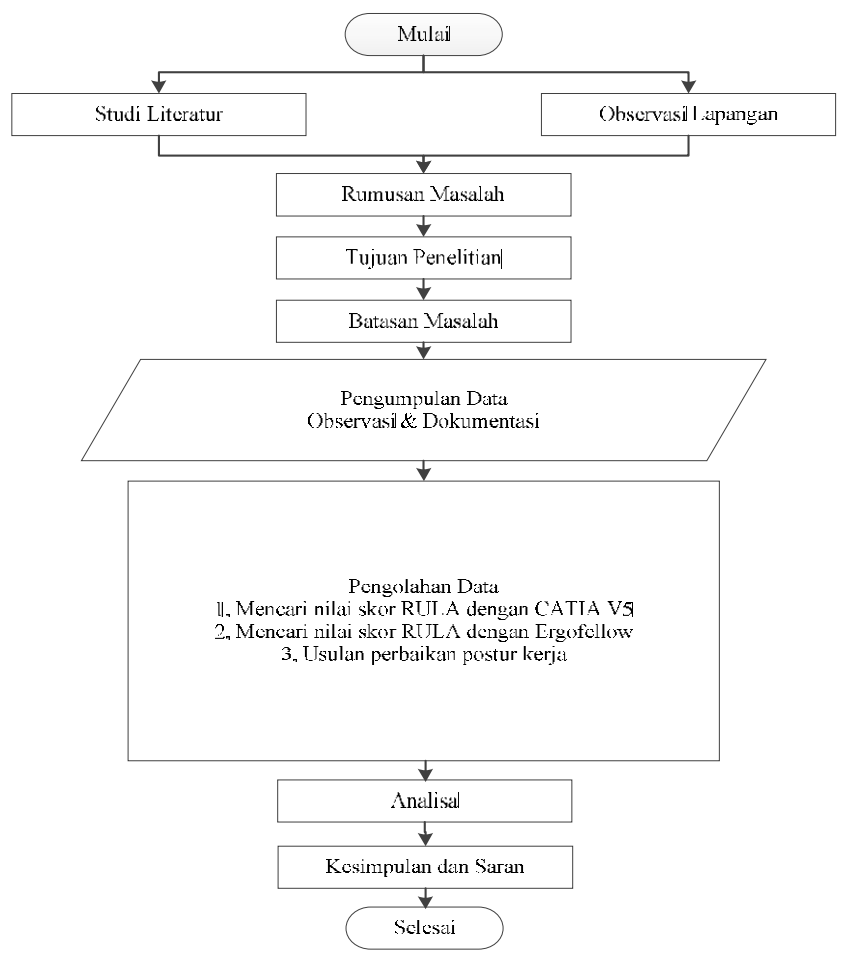

Gambar 1. Diagram Alir Penelitian

\section{HASIL DAN PEMBAHASAN}

Operator yang bekerja pada PT.XYZ pada gambar ini adalah operator bar bending yang sedang membuat ring besi, dengan observasi dan wawancara didapat berat besi ring sebesar $0.5 \mathrm{~kg}$.

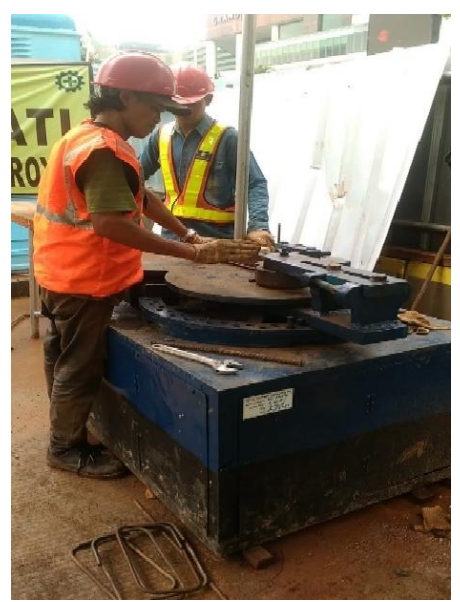

Gambar 2. Prosesbar bending

Pengolahan data dilakukan dengan pemotretan guna memudahkan input untuk mengolah pada software Catia V5 menggunakan mannequin dengan pemberian beban sebesar $0.5 \mathrm{~kg}$.
1. Hasil Postur Kerja dengan RULA Menggunakan Catia V5

Analisis postur kerja operator bar bendingmenggunakan mannequin dengan bantuan software Catia V5 yang diberi load $0.5 \mathrm{~kg}$ sesuai dengan berat dari besi ring yang dikerjakan operator didapat hasil pada tubuh sisi kiri (left side) dan tubuh sisi kanan (right side) seperti dapat dilihat pada Tabel 1 dibawah ini:

Tabel 1. Rekap hasil RULA analysis pada Catia V5

\begin{tabular}{|c|c|c|c|c|c|c|c|c|c|c|}
\hline \multirow{2}{*}{ Segment } & \multicolumn{5}{|c|}{ Left side } & \multicolumn{5}{|c|}{ Right side } \\
\hline & 1 & 2 & 3 & 4 & 5 & 1 & 2 & 3 & 4 & 5 \\
\hline Postur A & & & & & & & & & & \\
\hline Upper Arm & & & $\sqrt{ }$ & & & & $\sqrt{ }$ & & & \\
\hline Forearm & & $\sqrt{ }$ & & & & & $\sqrt{ }$ & & & \\
\hline Wrist & & $\sqrt{ }$ & & & & $\sqrt{ }$ & & & & \\
\hline Wrist Twist & $\sqrt{ }$ & & & & & $\sqrt{ }$ & & & & \\
\hline Muscle & $\sqrt{ }$ & & & & & $\sqrt{ }$ & & & & \\
\hline Postur B & & & & & & & & & & \\
\hline Neck & $\sqrt{ }$ & & & & & $\sqrt{ }$ & & & & \\
\hline Trunk & & & $\sqrt{ }$ & & & & & $\sqrt{ }$ & & \\
\hline Leg & $\sqrt{ }$ & & & & & $\sqrt{ }$ & & & & \\
\hline Final Score & & & & & $\sqrt{ }$ & & & & & \\
\hline
\end{tabular}

Berdasarkan Tabel 1 dapat dilihat tubuh sisi kiri (left side) postur A yang perlu mendapat perhatian (nilai 3) padaupper arm, dan postur B pada trunk. Hasil akhir untuk tubuh sisi kiri mendapat nilai 5 yang artinya harus ada investigasi lebih lanjut dan ada perbaikan.

Pada tubuh sisi kanan (right side) postur A yang perlu mendapat perhatian (nilai 3) ada pada trunk, dan mendapat hasil akhir 4 yang artinya harus ada investigasi lebih lanjut dan ada perbaikan. Investigasi lebih lanjut dan perbaikan pada kedua sisi kiri dan kanan ini harus dilakukan pemecahan masalah terkait postur kerja dari operator bar bending tersebut. Jadi postur kerja yang dilakukan operator saat ini memang perlu perbaikan sesuai dengan hasil akhir yang didapat pada software Catia V5.

2. Hasil Postur Kerja dengan RULA Menggunakan ErgoFellow

Hasil-hasil analisis RULA menggunakan ergofellow diuraikan sebagai berikut:

a. Hasil ergofellow didapatkan untuk upper arm pilihan yang tepat terjadi pada $20^{\circ}-45^{\circ}$

b. Hasil ergofellow didapatkan untuk lower arm menyesuaikan posisi lengan bawah dengan pilihan yang ada dan pilihan yang tepat terjadi pada $60^{\circ}-100^{\circ}$

c. Pada postur operator bar bending menyesuaikan pergelangan tangan (wrist) pilihan yang tepat terjadi pada $15^{\circ}-15^{\circ}$ dan pergelangan tangan ditekuk digaris tengah.

d. Hasil ergofellow didapatkan untuk menyesuaikan wrist twist berada pada posisi handsake

e. Pilihan yang tepat untuk menyesuiakan leher (neck) terjadi pada $10^{\circ}-20^{\circ}$ dan pergelangan leher terkadang memutar 
f. Untuk menyesuaikan badan (trunk) untuk pilihan yang tepat terjadi pada $0^{\circ}-20^{\circ}$ dan pergerakan badan terkadang memutar

g. Pada postur kerja operator menyesuaikan kedua kaki (legs) yang tepat adalah kaki berdiri dengan baik dan dalam keadaan seimbang

h. Untuk muscle use and load dengan pilihan yang ada yaitu dengan grup A (upper arm, lower arm, and wrist) postur kerja sebagian besar bergerak secara statis dan beban (load) tidak terlalu berarti. Grup B (neck, trunk, and legs) postur kerja sebagian besar bergerak secara statis dan beban tidak terlalu berarti

i. Pada bagian grand score dengan hasil skor yaitu 5 dan action level 3 artinya investigasi dan perubahan dibutuhkan segera.

\section{Rekomendaasi Perbaikan}

Salah satu cara mengurangi cedera yang disebabkan oleh postur kerja yang tidak ergonomis adalah dengan melakukan perancangan ulang fasilitas pendukung kerja atau menambahkan fasilitas kerja yang baru agar postur kerja para pekerja tersebut menjadi ergonomis. Fasilitas kerja yang diberikan pada penelitian ini berupa kursi sehingga operator proses bar bending dapat melakukan pekerjaannya yang berulang dengan jangka waktu yang lama tanpa kelelahan yang berarti. Berikut ini merupakan rekomendasi untuk perbaikan postur tubuh pekerja:

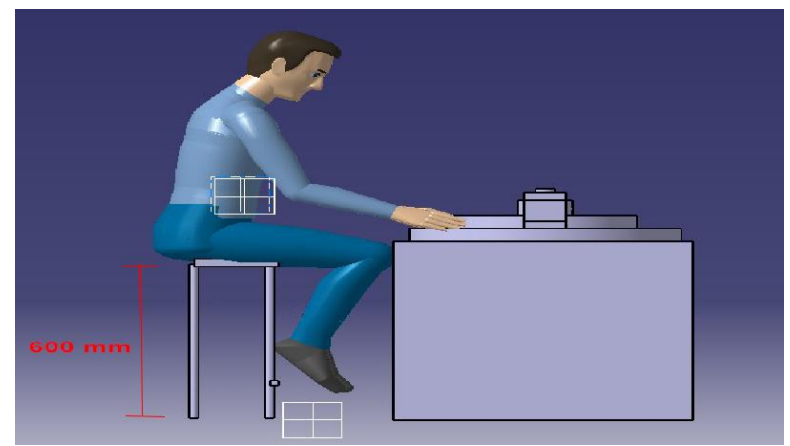

Gambar 3. Rekomendasi Perbaikan Postur Kerja Bar Bendingmengunakan mannequin

Berdasarkan pada analisis terhadap postur kerja saat melakukan pekerjaan bar bending pada besi yang akan dibuat menjadi ring dilakukan adanya perbaikan. Hal ini terkait dengan hasil akhir dari software CATIA V5 dan ErgoFellow yang rata-rata harus dilakukan perbaikan terhadap postur tubuh saat bekerja tersebut. Pada rekomendasi perbaikan diusulkan membuat kursi dengan bahan kayu setinggi $600 \mathrm{~mm}$ dimanapertimbangannya adalah menyesuaikan tinggi mesin bar bending, tinggi operator, beban dari besi ring dan pekerjaan yang berulang. Hasil lengkap perhitungan nilai RULA setelah perbaikan dapat dilihat pada Tabel 2 .

Tabel 2. Rekap hasil RULA analysissetelah perbaikan pada Catia V5

\begin{tabular}{ccccccc}
\hline \multirow{2}{*}{ Segment } & \multicolumn{3}{c}{ Left side } & \multicolumn{3}{c}{ Right side } \\
\cline { 2 - 7 } & $\mathbf{1}$ & $\mathbf{2}$ & $\mathbf{3}$ & $\mathbf{1}$ & $\mathbf{2}$ & $\mathbf{3}$ \\
\hline Postur A & & & & & & \\
Upper Arm & & $\sqrt{ }$ & & & $\sqrt{ }$ & \\
Forearm & & $\sqrt{ }$ & & & $\sqrt{ }$ & \\
Wrist & $\sqrt{ }$ & & & $\sqrt{ }$ & & \\
\hline
\end{tabular}

\begin{tabular}{ccccccc}
\hline \multirow{2}{*}{ Segment } & \multicolumn{3}{c}{ Left side } & \multicolumn{3}{c}{ Right side } \\
\cline { 2 - 7 } & $\mathbf{1}$ & $\mathbf{2}$ & $\mathbf{3}$ & $\mathbf{1}$ & $\mathbf{2}$ & $\mathbf{3}$ \\
\hline Wrist Twist & $\sqrt{ }$ & & & $\sqrt{ }$ & & \\
Muscle & $\sqrt{ }$ & & & $\sqrt{ }$ & & \\
Postur B & & & & & & \\
Neck & $\sqrt{ }$ & & & $\sqrt{ }$ & & \\
Trunk & & $\sqrt{ }$ & & & $\sqrt{ }$ & \\
Leg & $\sqrt{ }$ & & & $\sqrt{ }$ & & \\
Grand Score & & & $\sqrt{ }$ & & & $\sqrt{ }$ \\
\hline
\end{tabular}

Berdasarkan Tabel 2. Hasil perbaikan, nilai atau skor untuk tiap postur untuk tubuh sisi kiri berkurang terutama upper arm dari 3 menjadi 2, wrist dari 2 menjadi 1, dan trunk dari 3 menjadi 2. Hasil akhir untuk sisi bagian kiri pun berkurang dari 5 menjadi 3 . Begitupun dengan sisi tubuh sisi kanan terdapat pengurangan nilai yaitu trunk dari 3 menjadi 2 dan hasil akhir dari 4 menjadi 3. Dalam hal ini terjadi perbaikan skor sebelum menggunakan alat bantu dan sesudah menggunakan baik sisi kiri maupun kanan pada postur operator bar bending.

4. Hasil Analisis RULA setelah perbaikan menggunakan ErgoFellow

Hasil analisis RULA setelah perbaikan menggunakan ergofellow diuraikan sebagai berikut:

a. Hasil ergofellow didapatkan untuk upper arm terjadi pada $20^{\circ}-45^{\circ}$

b. Hasil ergofellow didapatkan untuk lower arm terjadi pada $60^{\circ}-100^{\circ}$

c. Hasil ergofellow setelah perbaikan pergelangan memiliki $0^{\circ}-15^{\circ}$ dan pergelangan tangan terkadang memanjang dan melengknng

d. Hasil ergofellow didapatkan untuk menyesuaikan wrist twist berada pada rentang menengah putaran

e. Pilihan yang tepat untuk leher (neck) terjadi pada $0^{\circ}$ $10^{\circ}$ dan pergelangan leher terkadang memutar

f. Untuk badan (trunk) tetap tegak terjadi pada $0^{\circ}$ dan terkadang memutar

g. Setelah menggunakan kursi pada postur kerja operator posisi kedua kaki adalah kaki dalam keadaan seimbang

h. Untuk muscle use and loadkarena beban yang digunakan tetap sama jadi sebagian besar bergerak secara statis dan beban tidak terlalu berarti

i. Pada grand score dengan hasil 3 dan action level2menunjukan bahwa diperlukan pemeriksaan lanjutan dan juga diperlukan perubahan-perubahan.

\section{SIMPULAN}

Pada postur kerja bar bending bagian yang mendapatkan skor tinggi dari tiap segmen merupakan trunk \& upper arm yaitu sebesar 3 pada kedua sisi tubuh. Hasil analisa postur RULA menggunakan CATIA V5 di dapat hasil akhir pada bagian tubuh sisi kiri dan sisi kanandibutuhkan investigasi lebih lanjut dan perbaikan.

Didukung dengan hasil Analisa RULA menggunakan ErgoFellow di dapatkan hasil akhir (final score) yaitu 5 dengan action level 3 yang artinya diperlukan investigasi lebih lanjut dan perbaikan yang harus dilakukan dengan segera, maka dari itu rekomendasi perbaikan yang diusulkan dengan menggunakan alat bantu atau fasilitas kursi pada 
pekerjaan bar bending yang memberikan hasil akhir dari analisis RULA menjadi berkurang.

Penelitian ini masih terdapat kekurangan terutama pada usulan perbaikan sehingga dapat dilakukan penelitian yang lebih baik pada penelitian selanjutnya untuk memberi variasi ilmu pengetahuan terutama mengenai analisa postur kerja.

\section{REFERENSI}

[1] BPS.go.id. 2019.

[2] Tarwaka. Ergonomi Industri, Dasar-Dasar Pengetahuan Ergonomi dan Aplikasi Di Tempat Kerja. Surakarta: Harapan Press. 2011.

[3] A. I. Sugiharto, D. Trihastuti, \& L. P. S. Hartanti, Analisis perbaikan postur dan metode kerja untuk mengurangi kelelahan muskuleskeletal di PT. XYZ Surabaya. Gema aktualita. Vol.2, No.2, 2013.

[4] S. P. Chakravarthy, \& S. K. M. Shekar, Ergonomic study of auotomobile assembly line. International Journal of recent technologies in mechanical electrical engineering (IJRMEE). Vol.2. 110-114. 2015. 